\title{
A política externa e geopolítica brasileira na era Lula: uma análise dos acordos de cooperação técnica para a África
}

\section{André Santos da Rocha}

\section{Introdução}

O presente texto é um produto parcial das pesquisas desenvolvidas acerca das relações de cooperação internacional entre o Brasil e os países africanos, na qual é tomado como recorte a últimas décadas - final do século XX e as iniciais do XXI. Trazemos à tona a importância de uma análise geográfica do mundo contemporâneo, que perpassa análise de conjuntura política, mas também de dados acerca da relação diplomática, econômica e técnicas que guardam as novas formas de projeções hegemônicas que transitam em outras roupagens, para além daquelas contidas classicamente na cooperação Norte-Sul. Neste caso estamos tratando especificadamente da Cooperação SulSul (CCS), que corresponde a aproximação entre os países do dito Sul Global indicado pela condição de periferia e/ou semiperiferia, ou mesmo emergente no sistema mundial (PAUTASSO,2010; ROCHA, 2016) ou como uma geopolítica Meridionalista. (SILVESTRE, 2014).

Já afirmamos que outros escritos (ROCHA, 2014) que no mundo contemporâneo emergem novas dinâmicas políticas, econômicas e culturais que provocam transformações na configuração mundial do poder. (AGNEW, 2008; CHOMSKY, 2004). Além disto entendemos que este contexto revela dimensões e expressões estratégicas, que reverberam na compreensão mais alargada da geopolítica, vista aqui para além da simples meta da dominação efetiva - material - do território por parte do Estado.

Neste sentido, indicamos que tomamos como horizonte analítico os apontamentos da Geopolítica Crítica (Ó TUATHAIL, 1996), e entendemos que a forma de compreensão das estratégias de projeção da dominação e controle territorial se traduzem em observar elementos mais sutis, que envolvem entender que outros atores, são também, atores geopolíticos (tais como a mídia, organizações criminosas, e o próprio grupos capitalistas, movimentos sociais, entre outros), que há necessidade de entender as representações - seja aqueles presentes na cartografia, seja nos discursos e imagens (CAIRO, 2008); e avaliar as formas de aproximação e associativismo que visam a estratégia de expansão de poder sem desconsiderar os efeitos materiais da dominação.

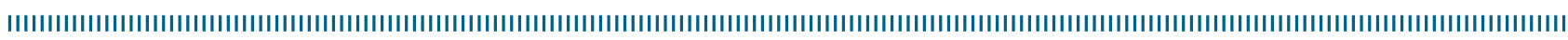
Como citar este artigo:

ROCHA, André Santos da "A política externa e geopolítica brasileira na era Lula: uma análise dos acordos de cooperação técnica para a África”. In: RÜCKERT, A. A.; SILVA, A. C. P. da; SILVA, G. de V. (Orgs.). Geografia Política, Geopolítica e Gestão do Território: integração sul-americana e regiões periféricas. Porto Alegre: Editora Letra1, 2018, p. 131-144 DOI 10.21507/9788563800367-08 
Neste sentido, compreendemos que a projeção hegemônica Brasileira na contemporaneidade a partir de sua política externa no contexto da CSS, indica a necessária investigação por parte da ciência geográfica. Tal empreitada se faz pertinente por dois motivos: [a] pelo plano empírico, porque o Brasil têm emergido e se consolidado no plano internacional tomando corpo hegemônico que salta para além das fronteiras do continente americano, trazendo novas perspectivas de inserção e projeção hegemônica e de territorialização de suas instituições e empresas num contexto de globalização; e [b] pelo plano teórico-metodológico, porque este período exige uma retomada do horizonte das estratégias espaciais presentes nas articulações internacionais que aparentemente não são nítidas, mas se fazem fundamentais. Isso ocorre, sobretudo, por uma ausência ou um silenciamento da Geografia, em especial na Geografia pela Brasileira, sobre a escala mundo com aprofundamento de estudos sistemáticos.

Diante disto, apresentaremos aqui a importância da Geografia na análise de um tema pouco usual no seu campo de análise: A política externa. Ela é compreendida como uma versão soft presente na roupagem das estratégias Geopolíticas. Assim, além de um resgate do entendimento e de uma aproximação entre política externa e geopolítica, indicaremos apontamentos acerca do período de 2003-2010, que compreende uma análise da conjuntura das ações de política externa no Governo Lula, que privilegiou uma orientação em torno da Cooperação Sul-Sul (CSS), com destaque para a aproximação com o continente Africano. E, por fim, apresentamos uma análise geográfica e geopolítica a partir da cartografia dos projetos de cooperação técnica entre o Brasil e o Países africanos, que se desenharam a partir da reorientação da política externa em prol das relações Sul-Sul, onde abordamos os projetos de cooperação nas áreas de maior demanda: agricultura, educação e saúde.

\section{Lançando bases para uma aproximação entre Política externa e geopolítica.}

A política externa não é um tema novo no campo das Ciências Humanas, tradicionalmente a maior parte dos estudos se concentram nas áreas de Relações Internacionais, História e Ciência Política. (CERVO, 2003 e 2002; e VISENTINI, 1995). Na Geografia a ênfase analítica e extremamente rarefeita e ao longo da tradicional escola geopolítica o tema foi pouco abordado. Todavia, no âmbito da Geografia Brasileira, professora Therezinha de Castro (1982), aborda a dimensão diplomática brasileira - em seu livro "O Brasil no Mundo Atual - posicionamento e diretrizes" ao tratar do "ciclo africano" em alusão as investidas diplomáticas dos governos Médici (1972), Geisel (1974) e Figueiredo (1980) com o continente africano, logo, ensaiava com o tema da política externa. Embora não use o termo para realizar suas análises, o conteúdo do que se tratara estava implícito na projeção sobre a Geopolítica que se desenhava.

A construção desta questão em torno da diplomacia - que entendemos como parte constituinte da política externa, traz na verdade o conteúdo das relações de poder em seu cerne. Que por sinal é primaz no contexto de qualquer análise Geopolítica (AGNEW et al. 2002) e que é pertinente neste contexto das dimensões políticas que envolvem poder e espaço e que varia segundo “atores, lugares e épocas. (RÒSIERE, 2007 apud SANGUIN, 2016, p. 19).

Neste sentido, concordamos com André-Louis Sanguin (2016, p.17) ao indicar que "os dois momentos da história recente - o desaparecimento do império Soviético e a ascensão dos BRICS" acabaram corroborando para uma nova retomada de estudos que pudessem responder a nova organização econômica e política do mundo, ultrapassando pressupostos antes consolidados. Neste sentido, entendemos que: o que se estabelece para este novo horizonte é a empreitada de descortinar o poder. Entendemos que uma análise 
de aproximação dos desdobramentos da política externa com a natureza da ciência geográfica, permitem acessar alguns recursos fundamentais do novo quadro geopolítico.

Recorrendo a uma definição para entender a política externa, Leticia Pinheiro (2004, p. 7) indica que ela pode ser entendida como:

(...) o conjunto de ações e decisões de um determinado ator, geralmente o Estado, em relação a outros Estados ou atores externos - tais como organizações internacionais, corporações multinacionais ou atores transnacionais - formulada a partir de oportunidades e demandas de natureza doméstica e/ou internacional.

A partir desta definição, percebe-se que ela está associada a "todo um conjunto de ações" [estas que se manifestas nos acordos, nas intervenções, nos associativismos, cooperação, etc.] e "decisões" [orientação de aproximação ou distanciamento que pode ser momentânea ou perene]. Num sentido mais amplo, busca-se na prática com a política externa exercer um trunfo de poder em relação a outro ator externo. O que de alguma forma se aproxima da leitura mais crítica de Geopolítica (LACOSTE, 2000) para quem esta é associada a qualquer processo que esteja relacionada a "tomada do poder" ou mesmo ao "exercício do poder" (RAFFESTIN, 1993) seja ele baseado numa dimensão bélica intervencionista, seja ela baseada numa perspectiva diplomática com pilares em acordos e consensos.

Desse modo, podemos entender que a Geopolítica está presente tanto nas práticas imperiais de dominação bélica (Hard Power), quanto nas estratégias discursivas e de associativismos de cooperação (Soft Power) uma vez que a construção de acordos, e outros mecanismos de dominação podem ser entendidos como trunfos de poder (RAFFESTIN, 1993), por viabilizarem que atores estruturem o exercício do poder - seja ele territorial seja ele diplomático.

Neste sentido, se a política externa sinaliza e delineia as estratégias de interesses de um ator frente ao mundo, podemos entender que indiferente da postura (Soft Power ou Hard Power) ela indica claramente pistas de trama geopolítica deste Ator, em especial porque a condição prática de política externa dos Estados, em maior ou menor grau, tece suas estratégias em torno da construção de Hegemonias - que entendemos como formas de exercício de poder.

Concordamos com Jonh Agnew (2008) para quem o termo hegemonia não deve ser confundida com a noção de império. O "exercício hegemonia"1 não deve confundido com a característica relacionada apenas a práticas coercitivas, espraiamento territorial em lógica zonal ou contígua, e a tentativa de se impor como poder supremo ou absoluto. No sentido mais amplo, a Hegemonia pode ser construída partir de acordos e difusão de valores, ter a arquitetura de operação territorial difusa e descontinua (rede), e tenta se revelar como um poder em liderança. É possível indicar que a construção de uma Hegemonia passa pela construção da percepção enquanto um país potência que não se distancia da forma de constituição do sistema mundo (ROCHA, 2014).

Ana Ester Ceceña (2008) argumenta que a configuração do poder mundial no contexto do final do século XX e início do XXI, passa necessariamente por um duplo entendimento: Há uma hegemonia do capital e uma hegemonia de Estado. A autora, a partir de uma concepção Gramsciana sinaliza que essa hegemonia é construída num sistema de valores (simbólicos e materiais) e de prática, que contextualizadas no período vigente se revela como parte inerente do ciclo de acumulação capitalista, o que indica, de certa forma, o modus operadis para a hegemonia de Estado. Os moldes da globalização neoliberal indicam o dinheiro como expressão de poder, ou seja, através da compra das mercadorias em

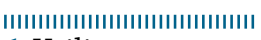

1 Utilizamos o termo "exercício da hegemonia" uma vez que apontamos que a Hegemonia é uma forma de exercício do poder. O Poder para Claude Raffestin (1993) a partir da leitura de Michel Foucault não pode ser compreendido fora de seu exercício dimensão prática. Ou seja, a compreensão da Hegemonia, como forma de poder, se faz na medida que entendemos como ela opera. 
âmbito internacional (comercio exterior), cessão de créditos, elaboração de acordos comerciais e políticas para o desenvolvimento pode-se projetar o "exercício da hegemonia" do Estado.

A questão que centralizamos aqui espraia de forma ampla essa filiação, uma vez que a política externa como uma estratégia de um ator frente a outro, indica uma nova forma de organização de poder. Assim, o alinhamento com um determinado país ou outro, pode indicar novas orientações geopolíticas.

No contexto atual, parte das ações de política externa de alguns países, como o exemplo do caso Brasileiro - que aqui será explorado mais a frente - tem primado por um exercício que perpassa o que chamamos de Cooperação Sul-Sul (CSS), ela pode ser entendida como o fortalecimento das relações econômicas e políticas entre países tidos como "periféricos e semiperiféricos" do chamado Sul Global. Essas aproximações demandam, para além da cooperação econômica, o incremento tecnológico e o desenvolvimento de infraestruturas territoriais e sociais.

Diferentes autores destacam a emergência deste tipo de cooperação desde os anos de 1970 e que se intensificaram ainda mais nos últimos anos. (KRASNER, 1989; PAUTASSO, 2010; LIMA, 2005; MILANI, 2012). Por vezes é apontado como uma modelo mais brando em oposição a constituição da forma vertical contido nas relações Norte-Sul. Todavia, não se pode ignorar que essa relação Sul-Sul, ocorrem num contexto de Hegemonia global do capital (CECEÑA, 2008), logo, assimetrias e lógicas de apropriação se desenvolvem conjuntamente (GARCIA,2012).

Num plano hegemônico, a política externa no contexto da CSS faz emergir consigo a linguagem da cooperação econômica e técnica, que se revelam como uma alternativa geopolítica de consolidação de outras formas de poder, que podem consolidar o Brasil num plano favorável na diplomacia mundial. Isto posto, que a construção das agendas desta cooperação não ocorrem por imposições, mas numa condição horizontal, chamada demand driven ${ }^{2}$.

Neste sentido, mais restrito a construção da hegemonia brasileira através de sua política externa, na construção para o arcabouço da cooperação Sul-Sul prima pelas respostas de demandas existente em países parceiros que percebem no Brasil a possibilidade de criar vínculos para o desenvolvimento. Neste sentido, afirma-se, o que já apontamos sobre os elementos de avaliação da projeção hegemônica brasileira, que envolvem: [a] perceber a capacidade de materiais no que tange a produção de uma tecnologia embrionária e expansão financeira; [b] a medida de auto percepção; e [c] a percepção de outros países do Brasil como potência emergente. (ROCHA, 2014).

Neste contexto, destacamos a compreensão desta orientação de política externa com base na CSS pela própria $A B C$ :

A política externa brasileira tem dimensão global, embora confira ênfase às relações mantidas com as nações com as quais o Brasil tem um patrimônio histórico, linguístico, cultural e étnico comum. Nesse arcabouço e em razão do extenso acervo de conhecimentos e de experiências disponíveis em inúmeras instituições nacionais, bem como à luz da capacidade brasileira de criar soluções inovadoras para problemas que se reproduzem em outros países em desenvolvimento, a cooperação técnica Sul-Sul brasileira compartilhada com países em desenvolvimento tem-se consolidado como um significativo instrumento de correção de assimetrias sociais e econômicas ${ }^{3}$. (ABC, 2015, Grifos nossos)

Ao entender a política externa como uma dimensão global, assume-se o caráter estratégico das ações que foi amplamente defendido como uma forma de posicionar o Brasil no sistema mundial. Abre-se destaque para a geopolítica discursiva da qual funda os princípios da CSS, no

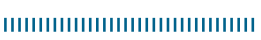

2 Termo usado para designar as demandas oriundas do país parceiro. O princípio utilizado pelo Brasil através da Agência Brasileira Cooperação $(\mathrm{ABC})$ para indicar a forma de construção da agenda de projetos e atividades isoladas, que passam necessariamente pela demanda inerente do país solicitante. Ou seja, O Brasil não propõe a parceria, a ele é solicitado. Isto revela uma dimensão de projeção Hegemônica - medida de percepção dos outros.

3 Informações disponíveis em <http://www.abc.gov.br/Gestao/ CooperacaoSulSul>. Acesso em: 15/08/2016. 
fato de ter "um patrimônio histórico, linguístico, cultural e étnico comum" coloca uma posição privilegiada ao país que possui uma geografia e uma história na composição do sistema-mundo muito similar aos demais países periféricos e semiperiféricos. Assim, a própria geografia e história colonial são agenciadas para justificar a aproximação com países latinos e africanos. Questões presentes em muitos discursos do expresidente Luiz Inácio Lula da Silva que os utiliza em menção a cooperação com estes países e para situar o Brasil com uma potência.

Neste sentido, emerge a questão do exercício do poder em uma construção hegemônica. Jonh Allen (2003) destaca que o exercício do poder pode ser interpretado de duas formas: sobre os outros e/ou com os outros. O poder sobre os outros recorre a uma dimensão impositiva, coercitiva de demandas próprias para os outros. A construção da hegemonia no sentido da liderança, com a orientação de uma política externa no contexto da CSS, que é (foi) ${ }^{4}$ parte da compreensão do Itamaraty entre 2003-2014, está centrado na construção do poder com os outros, na medida que assume as demandas dos países e percebe um diálogo que permite uma ajuda mútua para o desenvolvimento.

O argumento colocado, da condição de construção desde modelo de cooperação, evidencia o papel da política externa como um instrumento geopolítico. Aproxima-se em grande grau da perspectiva da Teoria Meridionalista de André Martin que assume tanto uma dimensão prática (baseada numa geoestratégia das políticas tecnológicas, do setor militar-defesa, dos recursos e do modus operadis do sistema produtivo) quanto "geoideológica" (no sentido de produzir outras formas des-coloniais de pensamento) em oposição daquela construção do padrão Norte-Sul. (SILVESTRE, 2014).

||I|||||||||||||||||||||||||||||||||||

4 Indicamos aqui que desde impeachment da presidente Dilma Rousseff, houve uma tomada da política externa brasileira para uma forma mais pragmática - voltadas para países que possam dar resposta objetivas - valorizando a aproximação com os países no norte (Estados Unidos e União Europeia).
Assim, entendemos a política externa no contexto da CSS como estratégia usada para alcançar aspirações brasileiras em escala mundial seja na conquista de assento permanente no conselho de segurança, seja na expansão econômica e reconhecimento brasileiro para além da porção sul-americana. Assim, a projeção da política externa Brasileira com continente africano no período de 2003 a 2010 merece lugar de destaque, todavia ainda é necessário entender essa construção histórica.

\section{Um resgate da política externa brasileira e as relações com a África - o papel da era Lula}

Segundo Paulo Visentini (2010) a relação entre Brasil e o continente africano não é uma realidade nova. Essa cooperação é posta numa relação histórica, que se estabelece por meio da escravidão (QUIJANO, 2005) na constituição do Sistema Mundo Moderno Colonial. (HAESBAERT; PORTO-GONÇALVES, 2006). Neste sentido, se estabeleceu uma interação geográfica onde "o Atlântico" se tornou o Pivô (PENHA, 1998) das relações de colonialidade de poder e subsidiou relações de hegemonia e territorialidade, vista até os dias atuais na presença maciça de imigrantes africanos, em especial de Angola e Moçambique, em cidades Brasileiras.

Numa linha cronológica ao longo da segunda metade do século XX, a década de 1960 é um marco na política externa brasileira, quando a PEI - Política Externa independente possibilitou ações internacionais por parte do Brasil direcionadas a interesses próprios dos países em desenvolvimento. Naquela ocasião, representou uma guinada diferenciada do tradicional modelo Norte-Sul, onde por mais que não haja uma exclusão, o modelo Sul-Sul veio inaugurando alternativas. Para Patrícia Soares Leite (2011) foi a Política Externa Independente do Governo Janio Quadros que esta perspectiva de compreensão da política externa do Brasil para o continente africano ganhou delineamento mais claro para atender interesses internos. Entretanto, Paulo Visentini 
(ibdem) sublinha que não houve continuidade desta ação para política externa brasileira durante a Guerra Fria, sobretudo no âmbito da ditadura militar. Conjuntura em que há um declínio do interesse brasileiro nas relações com a África. É importante considerar que o fato do governo brasileiro reconhecer independência de países no continente africano e respectivamente abrir embaixadas alguns destes países (MIYAMOTO, 2009) não expressa uma real aproximação com a perspectiva Sul-Sul e nem tem a África como proposição estratégica.

Esse certo "Pragmatismo" na política de alinhamento com o Norte - entendendo aqui a aproximação com os Estados Unidos e os países Europeus - cooperou com o "desinteresse" de aproximação com os países Africanos que se estende até os o início dos anos de 1990 com o Governo Collor.

A década de 1990 trouxe mudanças globais estruturais, e o próprio fim da Guerra Fria e do eixo Leste-Oeste faz com que a inserção geopolítica dos países pelo mundo também se modifique. $\mathrm{O}$ Brasil reaparece nas dinâmicas de poder e estreita relações com seus parceiros do sul global. Dentro de tal dinâmica, a década de 90 , portanto, pode ser vista como um marco nas estratégias brasileiras de reinserção internacional. É isso que o Brasil vem fazendo dentro das relações sul-sul, onde há um alinhamento de países emergentes que passam a projetar seu poder em âmbito regional e extra regional. (PAUTASSO, 2010). Nesse momento, o Brasil se consolida como um país intermediário na geometria de poder mundial (LIMA, 2005), e ainda é, simultaneamente, um país que recebe e fornece cooperação internacional. (MILANI, 2012).

Segundo Maria Regina Soares de Lima (2006) a mudança, ou indicação de transformação das orientações da política externa Brasileira, ganham espaço com os governos Fernando Henrique (1994-2002) e de Luiz Inácio Lula da Silva (2003-2010). A autora indica tendências sobre o caráter desta política externa, que alça dimensões em torno do prestígio internacional e de sua organização mais autonomista. Em ambos os governos, as cooperações com países africanos são retomados e se intensificam diante da conjuntura contemporânea em alternativa a crise que atinge os Estados Unidos e os países da União Europeia. (COSTA LIMA; MELO 2010). Todavia, Paulo Fagundes Visentini (2013) no seu livro “A projeção Internacional do Brasil 19302012", indica claramente que essa aproximação mais ampliada em torno das relações sul-sul e por conseguinte com a África, ganha maior projeção após 2003 com governo Lula.

O fortalecimento desse novo modelo - cooperação Sul-Sul - se dá a partir da virada do século XXI, com as semelhanças à PEI. Há um impulso explícito às relações internacionais brasileiras com a África desde então: "Valorizaremos a cooperação no âmbito da Comunidade dos Países de Língua Portuguesa"5, disse o chanceler Celso Amorim no discurso de posse do presidente em 2003.

A reinvindicação de uma filiação histórica e cultural com a África - presentes em muitos discursos do presidente Luiz Inácio lua da Silva ${ }^{6}$ - reforçam uma diplomacia que busca suas bases numa perspectiva cultural, que reforça como recursos simbólicos de filiação, além dos laços da escravidão, um histórico colonial e "terceiromundista" quase similar as bases da conferência de Bandung. Essa cooperação com os países africanos busca "fortalecer um vínculo político com uma região do mundo à qual nos unem entorno das afinidades culturais e laços históricos".

Para exemplificar a compreensão estratégica da articulação desta política externa em torno das relações sul-sul, que foi cativada para os países africanos, transcrevermos um trecho do discurso do ex-presidente que é bem característico desta construção "geoideológica" de pauta meridionalista:

||||||||||||||||||||||||||||||||||||||

5 Seis dos nove membros da CPLP estão no continente africano: Angola, Cabo Verde, Guiné-Bissau, Guiné Equatorial Moçambique e São Tomé e Príncipe. Os demais membros são Brasil, Portugal e Timor-Leste.

6 Ver os discursos de Luiz Inácio Lula da Silva disponíveis em < http://funag.gov.br/loja/download/505-discursos_selecionados_ lula.pdf >. Acesso em: 15/08/2016. 
O Brasil tem com a África laços profundos, que definem nossa própria identidade. Somos a segunda maior nação negra do mundo[...]. O comercio com a região cresceu exponencialmente: Aumentou $110 \%$ nos últimos quatro anos. A cooperação avançou. (Luiz Inácio Lula da Silva, 2006). ${ }^{7}$

O resgate do discurso presidencial foi uma maneira que utilizamos para iniciar a parte final de nossa argumentação. O contexto da política externa voltada para a cooperação Sul-Sul repercute como questão de continuidade do capital simbólico construído e é reafirmado no discurso presidencial - de base culturalista que fundamenta a aproximação entre países emergentes. Para a África esse discurso de projeto geopolítico meridionalista desenhou ações específicas de investimento diplomático. Visto, por exemplo, no aumento de número de embaixadas brasileiras abertas no período, da qual das 37 embaixadas no continente africano, 19 foram abertas ou reativas no período pós $2003^{8}$.

Também se fundamenta no ato que modifica estatuto do BNDES - o País redefiniu um marco para financiamento de capital privado brasileiro fora do País. Numa perspectiva de projeto expansionista que beneficia capitais privados Brasileiros como braços de sua expansão hegemônica e territorial, uma vez que muitas das empresas atuam no continente africano - tais como a Vale do Rio Doce, Petrobrás além de grandes empreiteiras como Odebrecht, OAS e Andrade Gutierrez.

Pois os avanços nos acordos comerciais e na aproximação diplomática foram amplamente tecidos em torno de uma política externa que primava por estabelecer as metas de ascensão do Brasil como país potencial na Escala mundo, que se utilizou da instituições e órgãos nacionais para projetar-se geopoliticamente no atual cenário internacional. Uma destas instituições é a $A B C$ - Agência Brasileira de Cooperação que é um órgão vinculado ao ministério das

\section{||||||||||||||||||||||||||||||||||||||||}

7 Trechos do Discurso do presidente Luiz Inácio Lula da Silva na abertura da cúpula África-América do Sul realizado em Abuja, Nigéria em 30 de novembro de 2006.

8 Informações disponível no BLOG do Itamaraty: <http://blog. itamaraty.gov.br/83-semana-da-africa>. Acesso em: 15/08/2016.
Relações Exteriores, que foi um estratégico para essa projeção brasileira. Pois ela é a responsável por organizar os acordos de Cooperação técnica (MILANI, 2017) - que em nossa interpretação são os elementos chaves que permitem o aumento da percepção da hegemonia Brasileira junto os países africanos e promovem sua captação diplomática.

Com base nos dados apresentados pela $A B C$ é possível visualizar a expansão do número de projetos e atividades isoladas de cooperação técnica para o continente Africano justamente após 2003 tendo seu ápice em 2010 - revelando a expressão da orientação da política externa Brasileira para o continente (ver gráfico 1 , na página seguinte).

A leitura do gráfico mostra a crescimento exponencial do número de projetos e atividades isoladas, que saiu de 17 no ano de 2003, chegando a número de 253 em 2010, que envolve 42 países no continente. Destaca-se também valor orçamentário para a África naquele ano, que ficou na ordem de 19.844,882,00 US\$. Valor que é superior ao destinado no mesmo período para América do Sul, Central, Norte e Caribe (14.009.188,00 US\$) e para a Europa, Ásia, Oceania e Oriente Médio (2.158.840,00 US\$) ${ }^{9}$.

Tal investimento, necessita ser melhor investigado, uma vez que estes projetos de cooperação técnica, espelham uma territorialização Brasileira no continente (ROCHA, 2016), com destaques para a área de Agricultura, Educação e Saúde.

\section{A face geopolítica da política externa nas relações Sul-Sul: cartografía dos projetos de cooperação para África}

Embora já se tenha exposto uma definição alargada de Cooperação Sul-Sul, não se pode negar que se refere a um termo polissêmico que indica

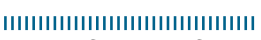

9 Verificar gráficos correspondentes - América do Sul e Caribe <http://www.abc.gov.br/Content/ABC/imagens/americas_ financeiro.png > ; e Asia, Europa, Oceania e Oriente Médio < http:// www.abc.gov.br/Content/ABC/imagens/asia_financeiro.png >. 
Gráfico 1. Execução financeiras de projetos e atividades Isoladas Brasileira para a África.

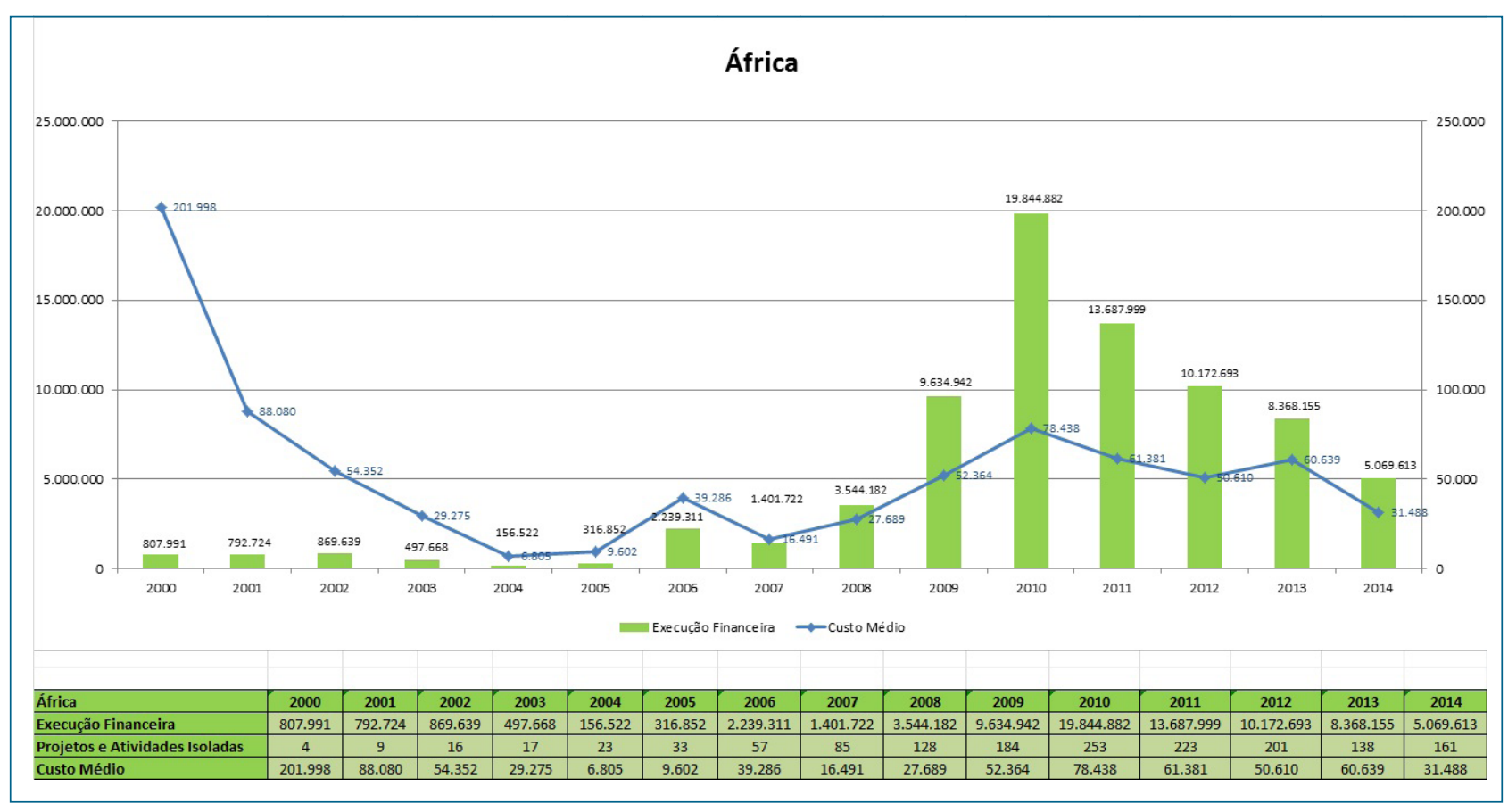

Fonte: ABC, 2014.

uma miríade de ações de política externa, entre as quais para Maria Regina Soares Lima e Carlos Milani (2016, p. 30):

Inclui a formação de alianças e coalizões em espaços multilaterais formais e ad hoc, acordos de comércio e investimentos, processos de integração regional, cooperação científica e tecnológica, cooperação técnica e cooperação para o desenvolvimento (Leite et al., 2015). Portanto, pode-se referir a formas políticas, comerciais, científicas e técnicas de cooperação entre os países do Sul.

Neste rol, pelo menos duas questões devem ser entendidas: [a] são estritamente estratégias para manutenção de ações no âmbito do Sul Global (KRASNER, 1989; PAUTASSO, 2010; LIMA, 2005); e [b] simbolizam ações que materializam dimensões geográficas, com por exemplo a partir dos modelos de integração regional e territorialização de instituições projetos de desenvolvimento. (ROCHA, 2014).

No caso da política externa brasileira no contexto da CSS, as iniciativas de cooperação técnica servem como importantes indicadores da projeção Hegemônica Brasileira neste tipo de cooperação, em especial porque:
[A] segue os trâmites de Demand Driving a construção de agendas desta cooperação não se dá por imposição, mas numa condição horizontal onde são obedecidas as demandas dos países solicitantes (ABC,2013);

[B] catalisa as potencialidades técnicas e produtivas Brasileiras - uma vez que as solicitações de parcerias de cooperação técnicas evidenciam o potencial em determinadas áreas na qual o Brasil possui expertise como nos exemplos da grande demanda de cooperação na área de Saúde, Educação e Agricultura.

[C] tem se colocado como uma possibilidade de correção de assimetrias - embora seja apontado pela própria Agência Brasileira de Cooperação como uma premissa da política externa no contexto da CSS. Não se pode ignorar que o modelo de desenvolvimento capitalista se revela extremamente assimétrico, logo tal discurso valida e fundamenta as projeções Brasileiras e seus projetos de alcance global sob o paradigma oposto contido na cooperação Norte-Sul 
No que tange a cooperação técnica brasileira, ela é formalmente associada a Agência Brasileira de Cooperação $(A B C)$ órgão ligado ao Ministério das Relações Exteriores que organiza e dá suporte aos projetos de cooperação técnica entre diferentes entidades Brasileiras com outros países do Mundo.

A grande questão que envolvem os projetos de cooperação técnica do Brasil com os países do continente africano no contexto da CSS e grande demanda para as áreas da Educação, Agricultura e Saúde. Neste sentido, fizemos uso dos dados disponíveis pela $A B C$ para mapear a distribuição espacial dos projetos e ações isoladas brasileiras nos países africanos bem como as instituições envolvidas nesta cooperação. Utilizamos o software QGis, que permitiram projetar espacialmente os números destes projetos e ações isoladas de cooperação - aqui limitados a cooperação técnica nas três áreas supracitadas. Essa cartografia produzida reflete uma geopolítica da CSS uma vez que ela indica claramente as projeções brasileiras em países que não eram privilegiados nas ações da política externa. Neste sentido apresentaremos cada cartografia e suas respectivas tendências de projeção hegemônica e territorial Brasileira:

\section{Projetos de cooperação na área da Agricultura}

Os projetos e atividades isoladas de cooperação técnica na área da agricultura envolvem aquelas atividades que se relacionam ao incremento e melhoria do setor agrícola, que tem entre outras atividades o melhoramento de sementes, técnicas de irrigação, técnicas de combate de pragas, formas de manejo do solo entre outras atividades.

O mapa 1, na página seguinte, foi elaborado com base de dados disponibilizados no site da $A B C$ sobre cooperação na área da Agricultura, que congregou a maior parte dos aportes financeiros com proporção de $33,35 \%$ de 2000 a $2014^{10}$.Indicamos que no referido mapa constam os projetos e atividades

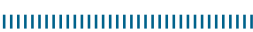

10 Informações presentes no relatório de Gestão 200 2014 da ABC. Disponível <http://www.abc.gov.br/Gestao/ AfricaSegmentoCooperacao>. Acesso em: 15/08/2016. isoladas que compõe as ações de cooperação técnica. Este segmento tem como marca a presença massiva da EMBRAPA como um parceiro executor na difusão de técnicas agrícolas que envolvem a pesquisa, o plantio, o melhoramento de sementes difusão de modos de cultivo, entre outras.

O mapa reforça a tendência de aproximação com os Países Africanos de língua português (PALOP's) - que agregaram entre projetos e atividades isoladas um total de 37 ações. Sendo em Cabo verde (5), Angola (6), Guiné-Bissau (7), São Tomé e Príncipe (8), e com destaque para Moçambique que agregou no levantamento o conjunto de 13 ações e projetos.

O mapa revela também o espraiamento Brasileiro para países falantes de língua inglesa e francesa, em especial na África Ocidental e Central, com destaques para Chade, Mali, Benin e Burquina-Faso que utilizam a plataforma de um projeto estruturante chamado Cotton-4, que sintetiza o apoio ao setor algodoeiro nos países partícipes com o aporte financeiro da $A B C$ na ordem de 5.219.451,00 US\$. Estas ações no setor algodoeiro marcam e o territorialidade da expansão tecnológica brasileira com projetos já em execução em outros países como Togo, Tanzânia e Senegal. A percepção do potencial tecnológico brasileiro também pode ser indicado na proporcionalidade das subáreas que caracterizam os projetos de cooperação na área de agricultura, com destaques para pesquisa, políticas públicas e cotonicultura.

\section{Projetos de Cooperação na área da Educação}

Os projetos e ações isoladas de cooperação técnica na área de educação contaram com cerca de 22,98\% do orçamento para Cooperação Técnica no período de 2000-2014. São aqueles que visam a colaboração com indicadores do quadro educativo, envolvendo formação de professores, ensino de língua portuguesa, formas de avaliação entre outras Atividades.

É oportuno destacar que este mapa (ver mapa 2) expressa ainda tendências já enraizadas de cooperação técnica com os PALOP's que concentram a maior quantitativo na área da 
Mapa 1. Projetos e ações isoladas de cooperação técnica Brasil com os países africanos na Área da Agricultura.

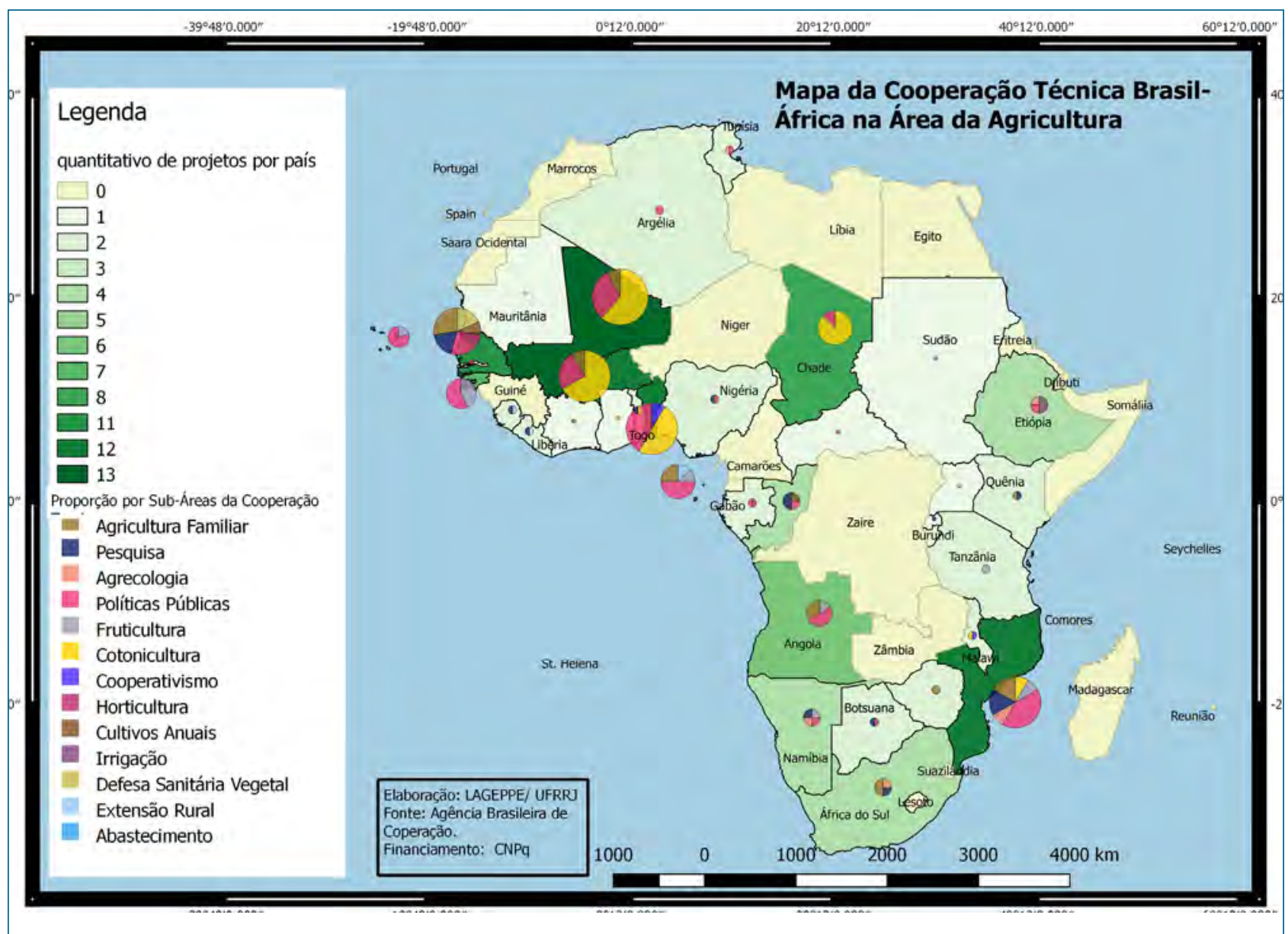

educação como é o caso de Moçambique (22), Cabo Verde (22), Angola (18), Guiné (22) Bissau e São Tomé e Príncipe (23). Ainda, é possível identificar tendências de aproximação com outros como Libéria, Mali, Tanzânia e Quênia.

Cabe destacar que no contexto da cooperação técnica em Educação a subárea com maiores demandadas é a de Formação profissional com 75 projetos e atividades isoladas relacionadas em diversos países que envolve desde a formação de professores até formação de quadros de nível médio e técnico. Essa demanda se faz, na maior parte do caso pela consolidação do Brasil como referência em políticas de formação de professores, maior Know-how em atividades de cunho técnicoempresarial e pelas filiações histórico e culturais com países lusófonos o que explica grande parte da demanda de cooperação técnica na área de educação, facilitada pela fonética na facilidade de transmissão de informações para qualificação em nível superior e em nível técnico para exercício profissional.

A exemplo os projetos estruturantes na área de educação mencionado pela $A B C$ estão localizados em países falantes da língua portuguesa e contam com parcerias diretas do Ministério da Educação e do SENAI na formação de quadros nestes países. Os investimentos somam quantias consideráveis, a saber: [a] Centro de Formação Brasil- Guiné Bissau - Fase II ( com parceria do SENAI) com o investimento total de 2.970.681,60 US\$; [b] Implantação do Centro de formação Brasil- Moçambique (com parceria do SENAI) com o investimento total 3.635.092,00 US\$; [c] Centro de Formação Profissional Brasil-São Tomé em Príncipe (com parceria do SENAI) com o investimento total de 4.073.428,00; e [d] UAB - Moçambique ( com parceria do MEC/CAPES) como investimento de 488.797,00 US\$. 
Mapa 2. Projetos e ações isoladas de cooperação técnica Brasil com os países africanos na Área de Educação

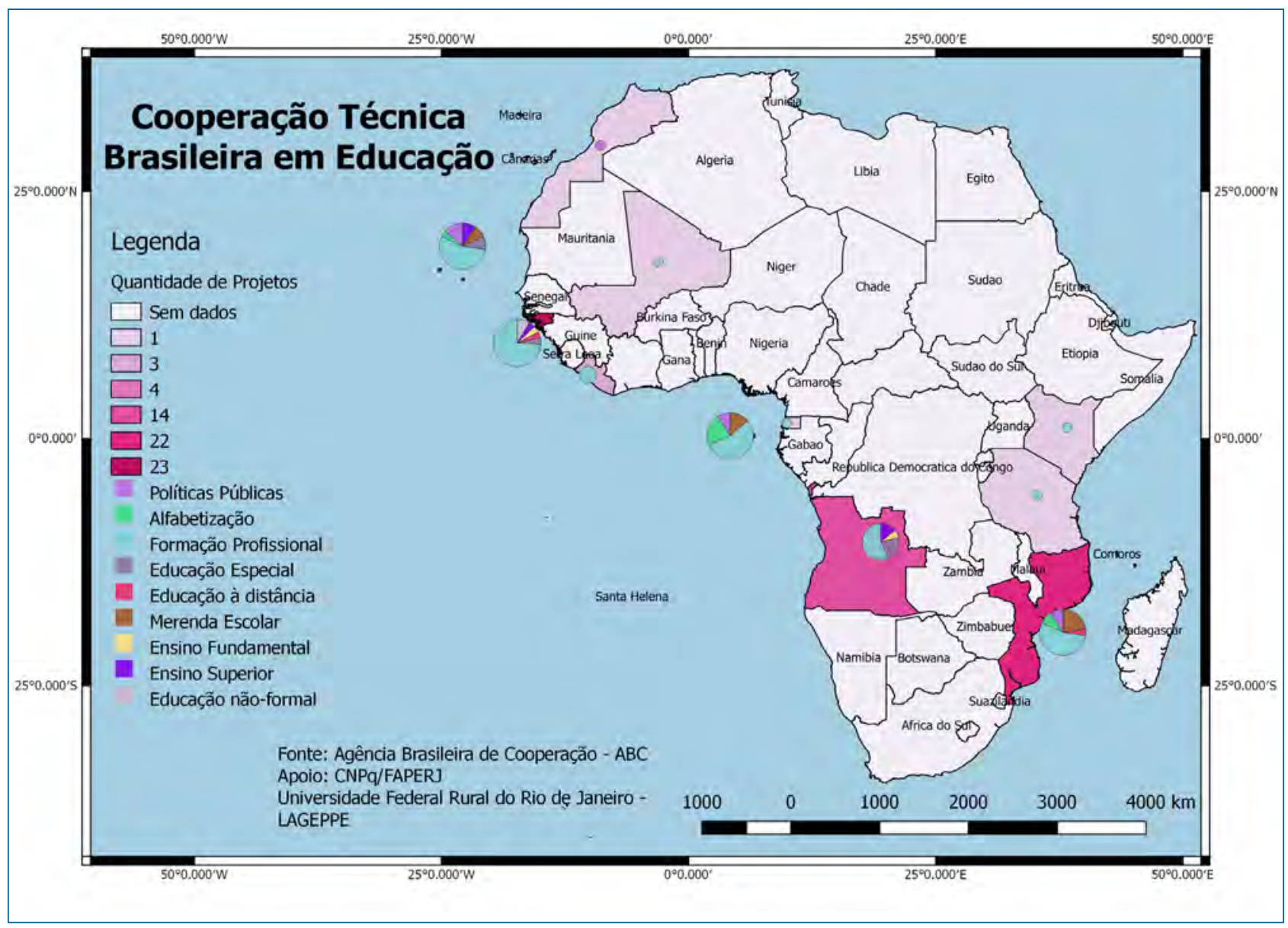

Além da presença de instituições governamentais (com a participação de universidades e outros centros de ensino e pesquisas públicos) a presença de instituições não governamentais como o SENAI representa a diversificação da territorialidade brasileira, que emana, mesmo no contexto da cooperação técnica, demandas da iniciativa privada e seu potencial no que tange ao exercício das ações de formação e qualificação profissional. O que atribui conjuntamente uma centralidade ao Brasil no campo de referência e prestígio cultural - elementos importantes na projeção de sua Hegemonia.

\section{Projetos de Cooperação da Área da Saúde}

Os projetos de atividades isoladas da área da Saúde receberam cerca $18,46 \%$ do orçamento da ABC no âmbito de 2000-2014 e contabilizou 136 projetos e atividades isoladas que estão espacializadas de modo singular.

A cooperação técnica na área de Saúde é bem diversificada, envolvendo desde projetos de criação de fábricas de medicamentos com transferência de tecnologia, fomento de políticas públicas de combate a doenças até formação e capacitação na área médica/hospitalar.

Esta área de cooperação técnica exemplifica bem o reconhecimento brasileiro no avanço do tema da saúde, com grande destaque da presença de instituições públicas brasileiras no continente, marcando um avanço da territorialidade de algumas instituições, com destaque para a FIOCRUZ e o INCA que se revelam hoje como importantes referências tecnológicas no campo da saúde.

No sentido de projeção espacial destacamos que o mapa 3 (na página seguinte) esboça o 
Mapa 3. Projetos e ações isoladas de cooperação técnica Brasil com os países africanos na Área de Saúde.

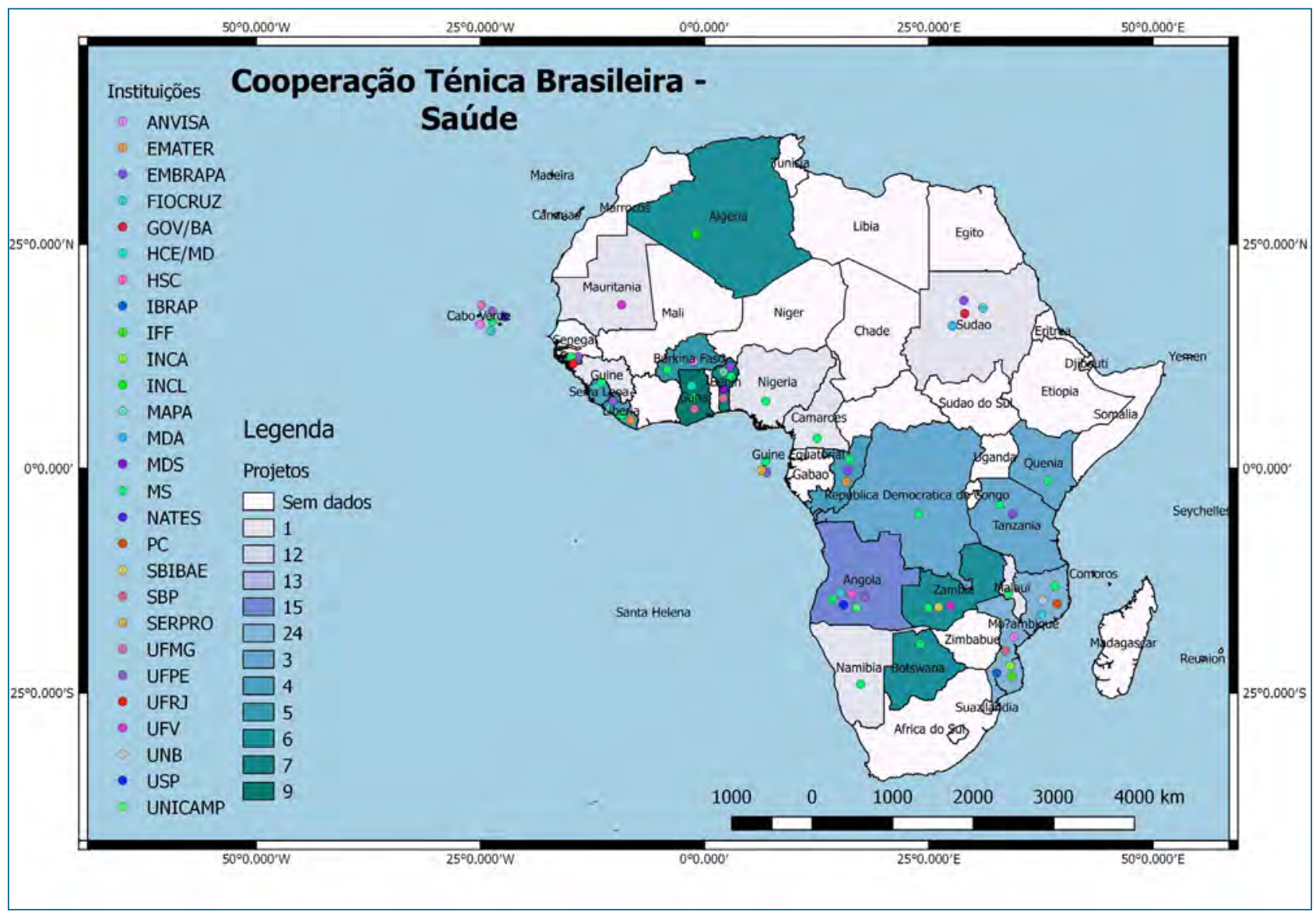

Fonte: $A B C$ - Agência Brasileira de Cooperação.

Org. LAGEPPE/UFRRJ - APOIO CNPq/FAPERJ

espraiamento Brasileiro em países com seus respectivos quantitativos esboçados no mapa: Guiné Equatorial (5), Benin (6) Burquina-Faso (5) Zâmbia (6), Botsuana (6), Argélia (7), Gana (9), e entre outros países. Destacamos ainda que este mapa indica a forte parceria dos PALOP's que concentram grande parte dos projetos de cooperação, com destaque para Moçambique com 24 projetos e atividades isoladas.

Essa diversificação para além dos PALOPS que fomenta a expansão espacial da hegemonia Brasileira é materializada, entre outras questões, no projeto estruturante de maior valor empregado que foi aplicado em Gana. O Centro de Hemoterapia e doenças falciforme Brasil-Gana é o projeto estruturante que contou com o apoio do Ministério da Saúde, da UFGM e do Hemominas e teve o valor empregado de 4.500.000,00 US\$. Além deste podemos destacar os inúmeros projetos de combate ao DST/AIDS.

No sentido hegemônico, a territorialização das instituições na área da saúde e a execução de projetos em países diferentes daqueles membros da CCPLP diversifica e amplia a área de sombreamento hegemônico do Brasil, e ao mesmo tempo consolida o país como uma referência tecnológica no campo da Saúde.

\section{Considerações Finais}

A política externa no âmbito da CSS, utilizada pelo Brasil serviu como elemento estratégico para uma nova agenda geopolítica para o mundo, que foi alimentada e reforçada no período de 20032010, tanto na dimensão quantitativa quanto qualitativa tendo o continente Africano como 
um trunfo espacial. Para além de um controle efetivo do território, os acordos de cooperação técnica produzem uma projeção hegemônica do Brasil, perceptível no seu potencial tecnológico e know-how de execução de políticas sociais na qual esses países vislumbram no Brasil a construção de parcerias.

A partir da elaboração da cartografia dos projetos de cooperação técnicas no contexto da CSS com maiores demandas pelos países Africanos, e com base nos valores de investimento disponibilizados pela Agência Brasileira de Cooperação $(A B C)$, vislumbra-se uma verdadeira estratégia geopolítica do Brasil que caminha na diversificação na aproximação com países africanos ampliando o leque, antes mais restrito aos PALOP's e agora ganhando espaço sobre a África Inglesa e Francesa ${ }^{11}$.

Os projetos de cooperação técnica- estabelecidos com os países do continente Africano induzem a pensar uma outra lógica de expansão de projeção de poder em escala mundial e regional, indo para além da influência nas antigas colônias portuguesas ao abrir janelas para uma nova agenda da Geopolítica Brasileira Meridionalista.

Por fim, partes destas parcerias no campo das relações Sul-Sul tem reverberado no apoio de países africanos do Brasil no Conselho de segurança da $\mathrm{ONU}^{12}$, uma vez que o projeto de cooperação tem servido como espaços de alianças entres estes países. Assim, reforça-se o papel e a importância desta estratégia como um elemento geopolítico mais amplo.

Neste sentido, a construção do poder, com os outros, a partir do agenciamento da política externa no contexto da CSS revela as estratégias de composição numa nova teia global de poder, que pode posicionar o Brasil neste novo sistema

\section{||IIIIIIIIIIIIIIIIIIIIIIIIIIIIIIIII}

11 Esses são os termos usados pela Própria $A B C$ para diferenciar os países dentro do continente Africano. Embora remeta a um olhar colonialista, entendemos que vislumbra ante de tudo um olhar geopolítico no entendimento que esses conjuntos linguísticos compõem e certa medida blocos de poder na qual o Brasil tem desenhado políticas diferenciadas.

12 Ver informações em: <http://agenciabrasil.ebc.com.br/ internacional/noticia/2015-01/angola-reafirma-apoio-ao-brasilno-conselho-de-seguranca-da-onu>. Acesso em: 15/11/2016. hierárquico em níveis econômicos e diplomáticos. Todavia, não podemos ignorar uma leitura de conjuntura da política nacional brasileira que após 2016, tem dado indícios de reorientações para um sentido mais pragmático, trazendo formas de associação com os Estados Unidos e a União Europeia. Os dados apresentados já indicavam um certo declínio dos investimentos da cooperação técnica no contexto da CSS com a África a partir de 2011, assim como para as demais regiões do globo.

Todavia os dados e informações aqui lançados servem para compor pistas analíticas de cunho geográfico neste contexto contemporâneo. Sua dinâmica em mutação certamente exigirá esforços contínuos com leituras mais aprofundadas acerca da geopolítica meridionalista sob a lógica da CSS seja num cenário de expansão ou retração. O que será que se anunciará? Quais as repercussões Geopolíticas para o Brasil neste novo contexto? Como a territorialização brasileira na África posiciona o Brasil na cooperação para o Desenvolvimento? Cremos que aí surgem novas demandas para pesquisa que valorizam as relações entre poder, política e Geografia.

\section{Referências}

ALLEN, Jonh. Power. In: Agnew, J. et all. A Companion to political Geography. Oxford: Blackwell, 2003. pp.95-108. AGÊNCIA BRASILEIRA DE COOPERAÇÃO. Manual da gestão da Cooperação técnica Sul-Sul. Brasília: ABC, 2013.

AGNEW, John. A nova Configuração do Poder Global. Revista Caderno CRH, Salvador, v. 21, n. 53, p. 207-219, Maio/ Ago. 2008.

AGNEW, J. et all. A Companion to political Geography. Oxford: Blackwell, 2003.

COSTA LIMA; Marcos Ferreira; MELO, Victor Denis Sousa. Revalorização do lugar da África: Política de desenvolvimento e as relações Sul-Sul no Governo Lula da Silva. SÉCULO XXI, Porto Alegre, V. 1, N¹,pp.127-155, jan-dez 2010

CAIRO, Heriberto. A América Latina no século XXI: geopolítica crítica dos Estados e os movimentos sociais, do conhecimento e da representação. Cad. CRH [online]. 2008, vol.21, n.53, pp.201-206

CASTRO. Therezinha. O Brasil no Mundo Atual posicionamento e diretrizes. Rio de Janeiro: Colégio Pedro II, 1982.

CECEÑA, Ana Ester. Hegemonia, emancipaciones y politicas de seguridad en América Latina. Lima, Clacso, 2008. 
CERVO, Amado Luiz. Política exterior e relações internacionais do Brasil: enfoque paradigmático. Revista Brasileira de Política Internacional. Vol. 46, n. 2. p.5-25, 2003

CERVO, Amado Luiz. Relações internacionais do Brasil: um balanço da era Cardoso. Revista Brasileira de Política Internacional, ano 45, n. 2, p. 5-35, 2002,

CHOMSKY, Noam. O Império Americano - Hegemonia ou Sobrevivência. São Paulo: Campus, 2004.

GARCIA, Ana E. Saggioro. A internacionalização de empresas brasileiras durante o governo Lula: uma análise crítica da relação entre capital e Estado no Brasil contemporâneo. 2012. Tese (Doutorado em Relações Internacionais). Instituto de Relações Internacionais - PUC-RJ, Rio de Janeiro, RJ

HAESBAERT, R; PORTO-GONÇALVES. A nova des-ordem mundial. São Paulo:EDUNESP, 2006.

KRASNER, Stephen D. Strucutural conflict. The Third World against global liberalism.Berkeley: University of California Press, 1985.

LEITE, Patrícia Soares. O Brasil e a cooperação sul-Sul em três momentos de política externa: os governos Jânio Quadros/ João Goulart,Ernesto Geisel e Luiz Inácio Lula da Silva. Brasília: Fundação Alexandre de Gusmão, 2011.

LIMA, M.RS; MILANI, C. Política Externa, Geopolítica e Modelos de Desenvolvimento. In: LIMA, Maria Regina Soares et all (org's). Cooperacion Sur-Sur, politica exterior y modelos de desarrollo en América Latina. Buenos Aires: CLASCSO, 2016. pp.21-39

LIMA, Maria Regina Soares. A política externa brasileira e os desafios da cooperação Sul-Sul. Rev. Bras. de Politica Internacional, 48 (1): 24-59 2005.

MILANI, Carlos. ABC 30 anos. História e desafios. Brasília: Agência Brasileira de Cooperação, 2017.

MILANI, Carlos. Aprendendo com a história: críticas à experiência da Cooperação Norte-Sul e atuais desafios à Cooperação Sul-Sul. Card.CRH, Salvador, v. 25, n. 65, p. 211-231, Maio/Ago. 2012

MIYAMOTO, Siguenoli. O Brasil e a comunidade dos países de língua portuguesa (CPLP). Revista Brasileira de Política
Internacional. Vol.52, ano 2. Jul/Dez, p.22-42, 2009

Ó TUATHAIL, Géaroid. Critical Geopolitics, Londres, Routledge, 1996.

PAUTASSO, Diego. O fortalecimento das relações sul-sul: estratégia e realidade para os países emergentes. Revista Conjuntural Austral, vol.2, no8 out-nov, 2010. pp.48-62.

PENHA, Eli Alves. Relações Brasil-África E Geopolítica Do Atlântico Sul', 280 f. Tese de Doutorado em geografia PPGG - Universidade Federal do Rio de Janeiro, 1998.

RAFFESTIN, Claude. Por uma Geografia do Poder. São Paulo: Ática, 1993.

QUIJANO, Anibal. Dom Quixote e os moinhos de vento na América Latina. Revista Estudos Avançados 19 (55),pp. 9-31, 2005.

ROCHA, André Santos. Território e Hegemonia no tear das Relações Internacionais na cooperação Sul-Sul: Apontamentos sobre a aproximação Brasil-África. In: Anais do I Congeo. Porto Alegre / Rio de Janeiro: Editora Letra1 /REBRAGEO, 2014, p. 39-48.

ROCHA, André Santos. Cooperação Sul-Sul como marco geopolítico e hegemônico na política externa brasileira: a Era Lula e a cooperação com a África. In : Anais do II Congeo. NATAL: REBRAGEO 2016 v. 1. p. 78-90.

SANGUIN. André-Louis. A evolução d Geografia Política desde os anos de 1990: uma perspectiva internacional. In: SILVA, A.C.P. Geografia Política, Geopolítica e Território: racionalidades e práticas em múltiplas escalas. Rio de Janeiro, Gramma, 2016, pp.13-64

SILVESTRE, Edu. A teoria geopolítica meridionalista de André Martin. Revista de Geopolítica, v. 5, n² 2, p. 5-18, jul./dez. 2014.

VISENTINI, Paulo Fagundes. A projeção Internacional do Brasil 1930-2012. São Paulo: Elseuvier, 2013.

VISENTINI, Paulo Fagundes. Cooperação Sul-Sul, diplomacia de prestígio ou imperialismo "soft"? as relações BrasilÁfrica no governo Lula. Século XXI, Porto Alegre, V. 1, No1, pp.65-84, jan-dez 2010

VISENTINI, Paulo Fagundes. Relações internacionais e desenvolvimento: o nacionalismo e a política externa independente (1951-1964). Petrópolis: Vozes, 1995.

* O presente texto apresenta uma versão ampliada do trabalho apresentado no II CONGEO - realizando em 2016 na cidade de Natal/ RN. Também apresenta os resultados já consolidados da pesquisa Financiado pelo CNPq através do edital Ciências Humanas e Sociais2014. Nesta ocasião, agradeço ao CNPq pelo auxílio financeiro da pesquisa bem como pela concessão de Bolsa de IC e a FAPERJ pela concessão das Bolsas de Iniciação científica que colaboram com o desenvolvimento do projeto, bem como as bolsistas Aline Braz e Jaqueline Bastos pela colaboração na coleta das informações.

\section{André Santos da Rocha}

Doutor em Geografia pela UFRJ. É Professor da Universidade Federal Rural do Rio de Janeiro (UFRRJ) atuando como docente Permanente do Mestrado em Geografia (PGGEO-UFRRJ) e na graduação em Geografia e Relações Internacionais. É Coeditor da Revista Continentes, e atualmente tem desenvolvido pesquisas sobre Geografia do Mundo contemporâneo com ênfase na Cooperação Sul-Sul com destaque para relação BrasilÁfrica e Brasil-América Latina.

E-mails: asrgeo@gmail.com; asrgeo@ufrrj.br 